\title{
Different Mechanisms Mediate Development and Expression of Tolerance and Dependence for Peripheral $\mu$-Opioid Antinociception in Rat
}

\author{
Kochuvelikakam O. Aley and Jon D. Levine \\ Department of Anatomy, Medicine, and Oral Surgery and Division of Neuroscience, University of California, \\ San Francisco, California 94143
}

The $\mu$-opioid [D-Ala ${ }^{2}, N$-Me-Phe ${ }^{4}$, Gly-ol $^{5}$ ]-enkephalin (DAMGO) exerts a peripheral antinociceptive effect against prostaglandin $E_{2}\left(P G E_{2}\right)$-induced mechanical hyperalgesia in the hindpaw of the rat. Tolerance and dependence develop to this effect. We have shown previously that tolerance and dependence can be dissociated and are mediated by different second messenger systems. In the present study, we evaluated whether the same or different second messenger systems mediate the development of this peripheral opioid tolerance or dependence compared with the expression of the loss of antinociceptive effect or rebound opioid antagonist hyperalgesia (i.e., expression of tolerance and dependence). DAMGO-induced tolerance was prevented by pretreatment with the nitric oxide synthase inhibitor $N^{G}$-methyl-L-arginine (NMLA) but not by the protein kinase $\mathrm{C}$ (PKC) inhibitor chelerythrine, the adenylyl cyclase inhibitor $2^{\prime}, 5^{\prime}$-dideoxyadenosine (ddA), or the calcium chelators 3,4,5trimethoxybenzoic acid 8-(diethylamino)-octyl ester (TMB-8) and 2-[(2-bis-[carboxymethyl]amino-5-methylphenoxy)-methyl]-6-methoxy-8-bis[carboxymethyl]aminoquinoline (Quin-2).
Once established, however, expression of DAMGO tolerance was acutely reversed by TMB-8 or Quin-2 but not by chelerythrine or NMLA. In contrast, naloxone-precipitated hyperalgesia in DAMGO-tolerant paws, a measure of dependence, was blocked by pretreatment with chelerythrine but not by NMLA, ddA, TMB-8, or Quin-2. Naloxone-precipitated hyperalgesia in DAMGO-tolerant paws was acutely reversed by chelerythrine, ddA, TMB-8, or Quin-2 but not by NMLA. Taken together, these results provide the first evidence that different mechanisms mediate the development and expression of both tolerance and dependence to the peripheral antinociceptive effect of DAMGO. However, although the development of tolerance and dependence are entirely separable, the expression of tolerance and dependence shares common calcium-dependent mechanisms.

Key words: protein kinase A; protein kinase $C$; nitric oxide; adenylyl cyclase; calcium; opioids; nociception; prostaglandin $E_{2}$
Opioids, which traditionally are thought to produce analgesia by actions in the CNS, also have antinociceptive actions in the periphery (Levine and Taiwo, 1989; Stein, 1991; Stein et al., 1995). Peripheral analgesic effects of opioids seem to be mediated via $\mu$-opioid receptors and a $\mathrm{G}_{\mathrm{i}^{-}}$and $\mathrm{G}_{\mathrm{o}}$-protein-mediated inhibition of the cAMP second messenger system in primary afferent nociceptors (Levine and Taiwo, 1989). We and others have reported previously that tolerance and dependence develop for this peripheral antinociceptive effect of $\mu$-opioid agonists (Aley et al., 1995; Kolesnikov et al., 1996). In the CNS a number of intracellular pathways have been suggested to play a role in opioid tolerance and dependence (Honore et al., 1997). Among these, $\mathrm{Ca}^{2+}$ (Wang et al., 1996), protein kinase C (Mao et al., 1995a,b; Narita et al., 1995), and nitric oxide (Herman et al., 1995; Pasternak et al., 1995; Vaupel et al., 1995; Dambisya and Lee, 1996; Dunbar and Yaksh, 1996) have been most thoroughly implicated. The mechanisms underlying peripheral opioid tolerance and dependence are less completely understood. Recent studies from our laboratory indicate a role for nitric oxide in peripheral toler-

\footnotetext{
Received June 6, 1997; revised August 1, 1997; accepted August 1, 1997.

This study was funded by National Institutes of Health Grant DE08973. We acknowledge our many discussions with Drs. Paul Green, Philip Heller, Gordon McCarter, David Reichling, and Kimberly Tanner.

Correspondence should be addressed to Dr. Jon D. Levine, Department of Anatomy, Box 0452, University of California, San Francisco, CA 94143-0452.

Copyright (C) 1997 Society for Neuroscience $0270-6474 / 97 / 178018-06 \$ 05.00 / 0$
}

ance and for protein kinase $\mathrm{C}$ (PKC) in peripheral dependence (Aley and Levine, 1997a,b). Because tolerance and dependence are initiated in $\sim 3 \mathrm{hr}$, but last for up to $24 \mathrm{hr}$, we hypothesized that different cellular signaling pathways may mediate the development of this opioid tolerance and dependence versus the loss of antinociceptive effect or rebound opioid antagonist-induced hyperalgesia (i.e., expression of tolerance and dependence). In the present study, we show that nitric oxide is involved in the development of $\left[\mathrm{D}-\mathrm{Ala}^{2}, N\right.$-Me-Phe ${ }^{4}, \mathrm{Gly}^{-\mathrm{ol}^{5}}{ }^{5}$-enkephalin (DAMGO)induced peripheral tolerance, whereas calcium-dependent mechanisms play a role in its expression. In contrast, $\mathrm{PKC}$ plays a role in the development of DAMGO dependence, whereas PKC, adenylyl cyclase, and calcium-dependent mechanisms play a role in its expression; thus, the development of tolerance and dependence are entirely separable, whereas the expression of tolerance and dependence share common calcium dependence.

\section{MATERIALS AND METHODS}

Animals. Experiments were performed on male Sprague Dawley rats (250-300 gm; Bantin-Kingman, Fremont, CA). Animals were housed in groups of two under a $12 \mathrm{hr}$ light/dark cycle. Food and water were available ad libitum. All testing was done between 10:00 A.M. and 4:00 P.M. Experiments were performed under approval of the Institutional Animal Care Committee of the University of California, San Francisco.

Behavioral testing. The nociceptive flexion reflex was quantified with a Basile Analgesymeter (Stoelting, Chicago, IL), which applies a linearly increasing mechanical force to the dorsum of the rat's hindpaw. Before 
the experiments, rats were exposed to the paw withdrawal testing procedure for $3 \mathrm{~d}$ ( $1 \mathrm{hr}$ daily at $5 \mathrm{~min}$ intervals); on the day of the experiment, rats were exposed to the same procedure, and the baseline threshold was determined as the mean of the six readings before the administration of test agents. The mean baseline threshold for the rats used in these experiments was $112.9 \pm 0.4 \mathrm{gm}$ (mean $\pm \mathrm{SEM} ; n=316)$. The mechanical nociceptive threshold was redetermined at three time points $(15,20$, and $25 \mathrm{~min})$ after treatments. The mean of these three readings was considered the paw withdrawal threshold attributable to drug administration, and this value was used to calculate the percentage change from the baseline threshold.

Drug administration. The drugs used in this study were prostaglandin $\mathrm{E}_{2}\left(\mathrm{PGE}_{2}\right.$; an inflammatory mediator; $\left.100 \mathrm{ng}\right)$, naloxone methyliodide (NAL; a quaternary opioid antagonist; $200 \mathrm{ng}$ ), 3,4,5-trimethoxybenzoic acid 8-(diethylamino)-octyl ester (TMB-8; a calcium chelator; $1 \mu \mathrm{g}$ ), 2-[(2-bis-[carboxymethyl] amino-5-methylphenoxy)-methyl]-6-methoxy8-bis[carboxymethyl] aminoquinoline (Quin-2; a calcium chelator; $1 \mu \mathrm{g}$ ), $N^{\mathrm{G}}$-methyl-L-arginine (NMLA; a nitric oxide synthase inhibitor; $1 \mu \mathrm{g}$ ), and dimethylsulfoxide (DMSO; a vehicle), all from Sigma (St. Louis, MO); DAMGO (a $\mu$-opioid receptor agonist; $1 \mu \mathrm{g}$ ) from Research Biochemicals (Natick, MA); chelerythrine-HCl (Ch; a PKC inhibitor; 1 $\mu \mathrm{g}$ ) from L. C. Laboratories (Woburn, MA); and 2',5'-dideoxyadenosine (ddA; an adenylyl cyclase inhibitor; $1 \mu \mathrm{g}$ ), a generous gift from Dr. Roger Johnson (State University of New York, Stony Brook, NY). The selection of the drug doses used in this study was based on the dose-response curves determined during previous studies (Aley and Levine, 1997a,b). The stock solution of $\mathrm{PGE}_{2}(10 \mu \mathrm{g} / 2.5 \mu \mathrm{l})$ was prepared in pure ethanol, and further dilutions were made in saline; the final concentration of ethanol was $\leq 1 \%$. DAMGO, naloxone, and NMLA were dissolved in saline. Chelerythrine was dissolved in deionized water. TMB- 8 and Quin-2 were dissolved in DMSO. All drugs administered intradermally were in a total volume of $2.5 \mu \mathrm{l} / \mathrm{paw}$. Whenever an antagonist was included, it was injected first. When drug combinations were used, they were administered from the same syringe in such a way that the drug mentioned first reached the intradermal site first. The drugs were separated in the syringe by a small air bubble to prevent drugs mixing while in the syringe; each bubble was $2.5 \mu \mathrm{l}$.

Statistical analysis. Data are presented as mean \pm SEM of six or more observations in each of the experimental groups. Statistical significance was determined by ANOVA followed by Scheffe's post hoc test, in which $p<0.05$ was considered statistically significant. The data for groups in some experiments are repeated in more than one figure for ease of comparison.

\section{RESULTS}

\section{Tolerance}

Three hourly injections of DAMGO $(1 \mu \mathrm{g})$ produced tolerance to its antinociceptive effect against $\mathrm{PGE}_{2}$-induced hyperalgesia. That is, when DAMGO was administered with $\mathrm{PGE}_{2} 1 \mathrm{hr}$ after the last injection of DAMGO alone, DAMGO was not antinociceptive against $\mathrm{PGE}_{2}$-induced hyperalgesia (Fig. $1 A$, $D A M G O+P G E_{2}$ vs $\left.D A M G O \times 3, D A M G O+P G E_{2} ; p<0.05\right)$.

\section{Second messengers involved in the development of tolerance}

When NMLA $(1 \mu \mathrm{g})$, which interferes with the production of the second messenger nitric oxide (NO), was combined with three hourly injections of DAMGO, the induction of DAMGO-induced tolerance was prevented [Fig. $1 A, D A M G O \times 3, D A M G O+P G E_{2}$ vs $\left.(N M L A+D A M G O) \times 3, D A M G O+P G E_{2} ; p<0.05\right]$. NMLA had no effect on baseline threshold (Fig. $1 A, N M L A$ ) but attenuated $\mathrm{PGE}_{2}$-induced hyperalgesia (Fig. $1 A, N M L A+P G E_{2}$ ). However, $1 \mathrm{hr}$ after three hourly doses (i.e., when tolerance to DAMGO was tested), there was no residual effect of NMLA on $\mathrm{PGE}_{2}$-induced hyperalgesia (Fig. $1 A, N M L A \times 3, P G E_{2}$ ). These results suggest that $\mathrm{NO}$ plays a role in development of DAMGOinduced tolerance.

Chelerythrine $(1 \mu \mathrm{g})$, a protein kinase $\mathrm{C}$ inhibitor, did not have any effect on baseline paw withdrawal threshold, $\mathrm{PGE}_{2}$ induced hyperalgesia, antinociceptive effect of DAMGO against
$\mathrm{PGE}_{2}$-induced hyperalgesia, or the development of DAMGOinduced tolerance [Fig. $1 B, C h+P G E_{2}, C h+D A M G O+P G E_{2}$, $\left.(C h+D A M G O) \times 3, D A M G O+P G E_{2}\right]$.

ddA $(1 \mu \mathrm{g})$, an inhibitor of adenylyl cyclase, had no effect on baseline paw withdrawal threshold (Fig. 1C) but attenuated $\mathrm{PGE}_{2}$-induced hyperalgesia (Fig. $1 C, d d A+P G E_{2}$ ). After three hourly doses of ddA, there was no residual effect at the next hour on $\mathrm{PGE}_{2}$-induced hyperalgesia (Fig. $1 C, d d A \times 3, P G E_{2}$ ). ddA did not prevent the development of DAMGO-induced tolerance [Fig. $\left.1 C,(d d A+D A M G O) \times 3, D A M G O+P G E_{2}\right]$.

TMB-8 $(1 \mu \mathrm{g})$ and Quin-2 $(1 \mu \mathrm{g})$, intracellular calcium chelators, did not have any effect on baseline paw withdrawal threshold, $\mathrm{PGE}_{2}$-induced hyperalgesia, the antinociceptive effect of DAMGO against $\mathrm{PGE}_{2}$-induced hyperalgesia, or the induction of DAMGO-induced tolerance [Fig. 1, D, TMB+PGE , $T M B+D A M G O+P G E_{2},(T M B+D A M G O) \times 3, D A M G O+P G E_{2}$; $E$, Quin $+P G E_{2}$, Quin $+D A M G O+P G E_{2},(Q u i n+D A M G O) \times 3$, $\left.D A M G O+P G E_{2}\right]$. DMSO (vehicle for TMB-8 and Quin-2) did not have a significant effect on baseline paw withdrawal threshold (data not shown).

These data suggest that nitric oxide, but not PKC, adenylyl cyclase, or calcium-dependent mechanisms affected by TMB-8 or Quin-2, plays a role in the development of tolerance.

\section{Expression of tolerance}

In DAMGO-tolerant paws, TMB-8 or Quin-2 with DAMGO plus $\mathrm{PGE}_{2}$ at the fourth hour was found to block the expression of tolerance (Fig. 2, DAMGO $\times 3, D A M G O+P G E_{2}$ vs $D A M G O \times 3$, $T M B+D A M G O+P G E_{2}, \quad D A M G O \times 3, D A M G O+P G E_{2} \quad$ vs $D A M G O \times 3, Q u i n+D A M G O+P G E_{2} ; p<0.05$ for all comparisons), indicating that calcium-dependent mechanisms are involved in the expression of tolerance. NMLA, which prevented the development of tolerance, and chelerythrine had no effect on the expression of DAMGO-induced tolerance (Fig. 2, $D A M G O \times 3, D A M G O+P G E_{2}$ vs $D A M G O \times 3, C h+D A M G O+$ $P G E_{2}, D A M G O \times 3, D A M G O+P G E_{2}$ vs $D A M G O \times 3, N M L A+$ $D A M G O+P G E_{2} ; p>0.05$ for all comparisons), indicating that neither PKC nor nitric oxide plays a role in the expression of DAMGO-induced peripheral tolerance. In the DAMGO-tolerant animal, NMLA did not exert an antinociceptive effect against $\mathrm{PGE}_{2}$-induced hyperalgesia, as it does in the nontolerant animal (data not shown).

\section{Dependence}

Naloxone methyliodide given at its dose to produce $80 \%$ inhibition $\left(\mathrm{ID}_{80}\right)$ for the inhibition of the antinociceptive effect of DAMGO (200 ng) (Aley and Levine, 1997a,b), when injected $1 \mathrm{hr}$ after the third of three hourly injections of DAMGO, precipitated withdrawal hyperalgesia (Fig. 3, $D A M G O \times 3, V$ vs $D A M G O \times 3$, $N A L ; p<0.05)$.

\section{Development of dependence}

When chelerythrine $(1 \mu \mathrm{g})$ was coinjected with three hourly injections of DAMGO, naloxone-precipitated withdrawal hyperalgesia was prevented [Fig. 3, DAMGO $\times 3, N A L$ vs $(C h+D A M G O) \times 3, N A L ; p<0.05]$, indicating a role for $\mathrm{PKC}$ in the development of DAMGO-induced dependence. Chelerythrine did not have any effect on the baseline paw withdrawal threshold (Fig. 1B).

Coadministration of NMLA, ddA, TMB-8, or Quin-2 with three hourly injections of DAMGO had no effect on the development of naloxone-precipitated withdrawal hyperalgesia 
[Fig. 3, DAMGO $\times 3, N A L$ vs $(N M L A+D A M G O) \times 3, N A L$, $D A M G O \times 3, N A L$ vs $(d d A+D A M G O) \times 3, N A L, D A M G O \times 3$, $N A L$ vs $(T M B+D A M G O) \times 3, N A L, D A M G O \times 3, N A L \quad$ vs $($ Quin $+D A M G O) \times 3, N A L ;$ all $p>0.05]$. These results indicate that nitric oxide, adenylyl cyclase, and calcium-dependent mechanisms dependent on TMB-8 or Quin-2 do not play a role in the development of DAMGO-induced peripheral tolerance.

\section{Expression of dependence}

Coadministration of chelerythrine, ddA, TMB-8, or Quin-2 with naloxone at the fourth hour after three hourly injections of DAMGO blocked precipitated withdrawal hyperalgesia (Fig. 4,

\section{A}

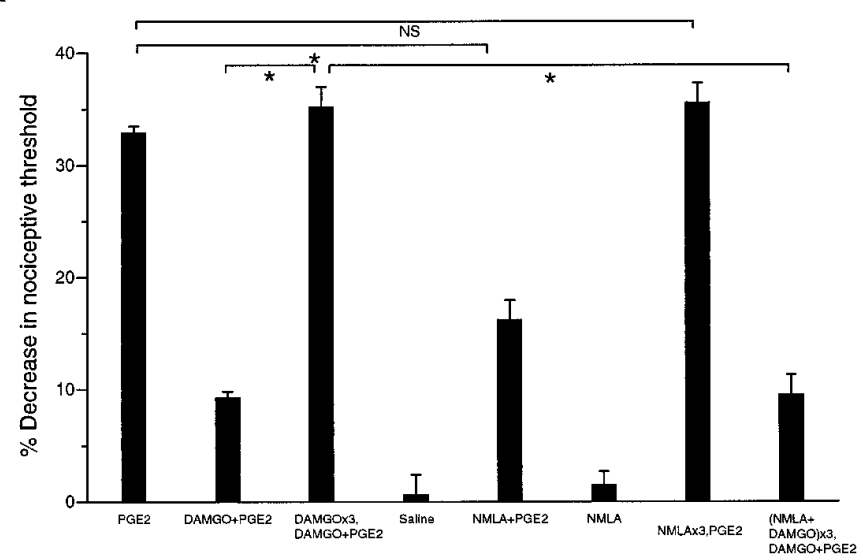

C

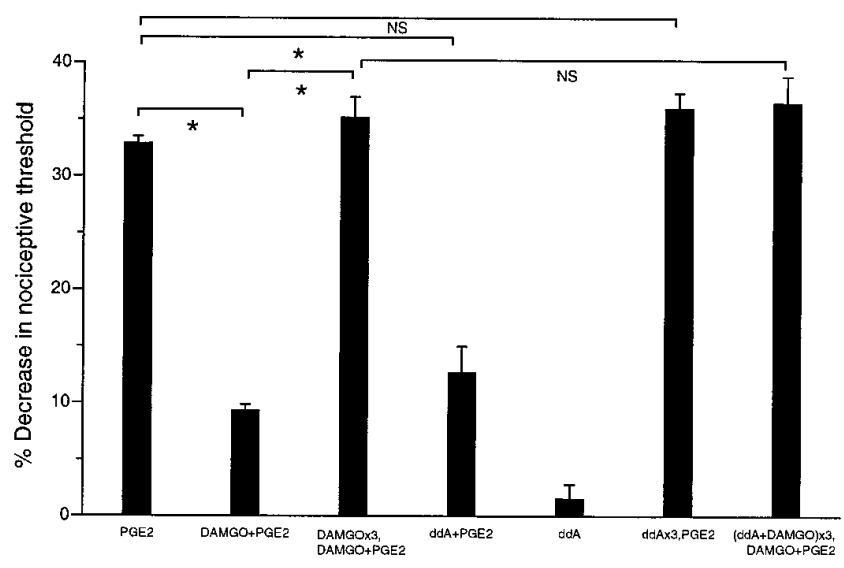

E

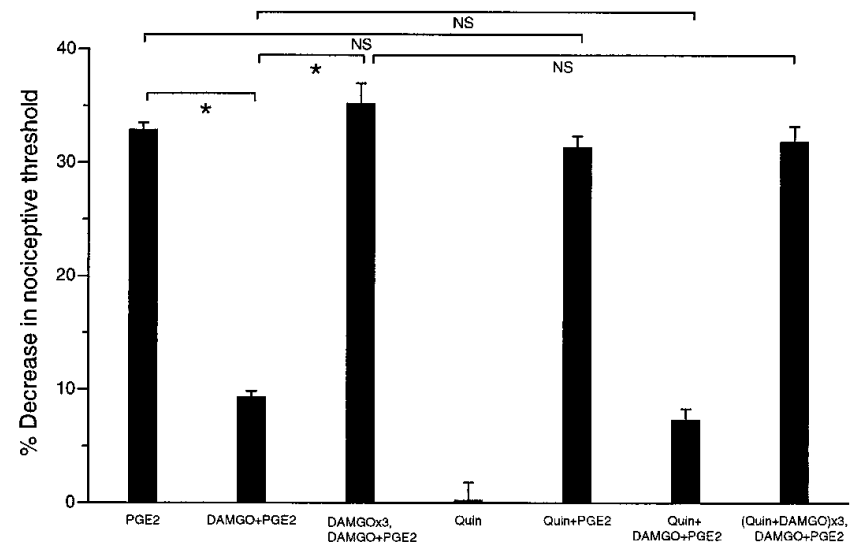

$D A M G O \times 3, N A L$ vs $D A M G O \times 3, C h+N A L, D A M G O \times 3, N A L$ vs $D A M G O \times 3, d d A+N A L, D A M G O \times 3, N A L$ vs $D A M G O \times 3, T M B$ $+N A L, D A M G O \times 3, N A L$ vs $D A M G O \times 3, Q u i n+N A L$; all $p<$ $0.05)$. Coadministration of NMLA with naloxone at the fourth hour after three hourly injections of DAMGO did not block naloxone-precipitated withdrawal hyperalgesia (Fig. 4, $D A M G O \times 3, N A L$ vs $D A M G O \times 3, N M L A+N A L ; p>0.05)$. These results indicate that $\mathrm{PKC}$, adenylyl cyclase, and calciumdependent mechanisms, but not nitric oxide, are involved in the expression of DAMGO-induced peripheral dependence (naloxone-precipitated withdrawal hyperalgesia).

B

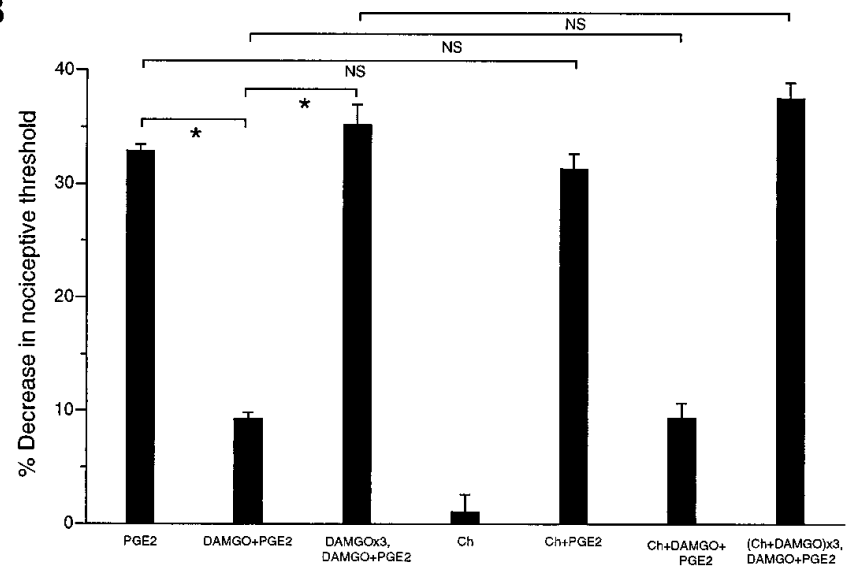

D

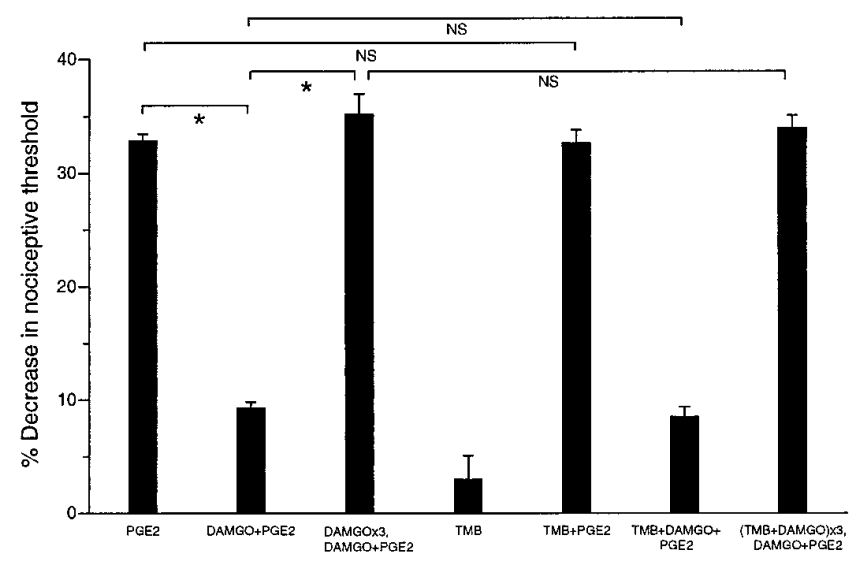




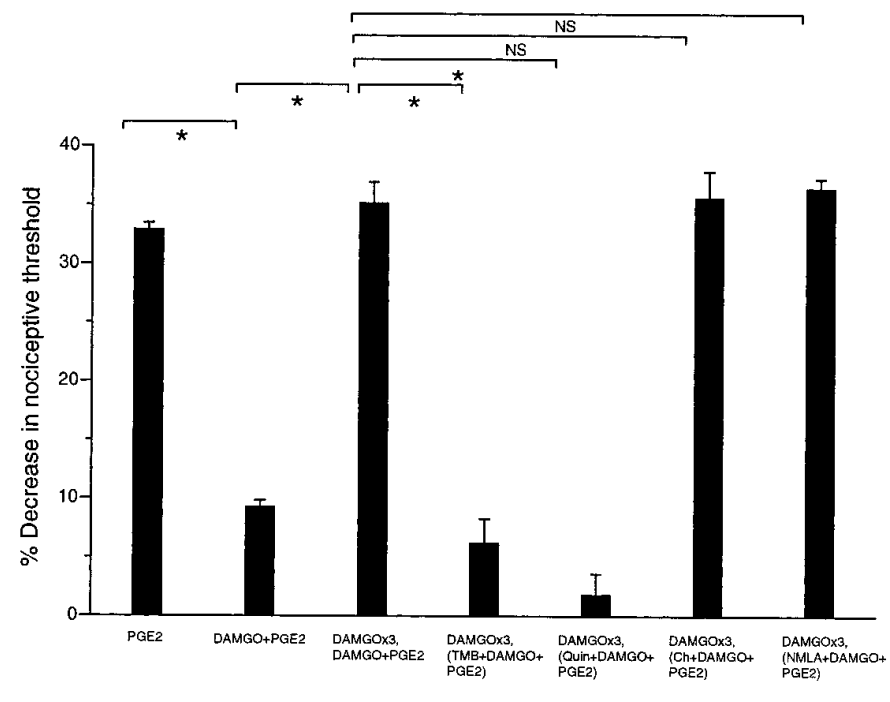

Figure 2. Calcium but not $\mathrm{PKC}$ or NO plays a role in the expression of peripheral opioid tolerance. Effects of $\mathrm{PGE}_{2},\left(P G E_{2} ; n=16\right)$, DAMGO plus $\mathrm{PGE}_{2}\left(D A M G O+P G E_{2} ; n=16\right)$, three hourly injections of DAMGO followed by DAMGO plus $\mathrm{PGE}_{2}(D A M G O \times 3$, $\left.D A M G O+P G E_{2} ; n=12\right)$, three hourly injections of DAMGO followed by TMB-8 plus DAMGO plus $\mathrm{PGE}_{2}$ at the fourth hour $\left(D A M G O \times 3, T M B+D A M G O+P G E_{2} ; n=6\right)$, three hourly injections of DAMGO followed by Quin-2 plus DAMGO plus $\mathrm{PGE}_{2}$ at the fourth hour $\left(D A M G O \times 3\right.$, Quin $\left.+D A M G O+P G E_{2} ; n=6\right)$, three hourly injections of DAMGO followed by chelerythrine plus DAMGO plus $\mathrm{PGE}_{2}$ at the fourth hour $\left(D A M G O \times 3, C h+D A M G O+P G E_{2} ; n=12\right)$, and three hourly injections of DAMGO followed by NMLA plus DAMGO plus $\mathrm{PGE}_{2}$ at the fourth hour (DAMGO $\left.\times 3, N M L A+D A M G O+P G E_{2} ; n=6\right)$ on mechanical paw withdrawal threshold in rats.

A summary of the second messengers implicated in the development and/or expression of tolerance and dependence to the peripheral antinociceptive effects of the $\mu$-opioid DAMGO is shown in Table 1.

\section{DISCUSSION}

In the present study, we have begun to dissect the mechanisms involved in the development compared with the expression of opioid tolerance and dependence in the model of peripheral

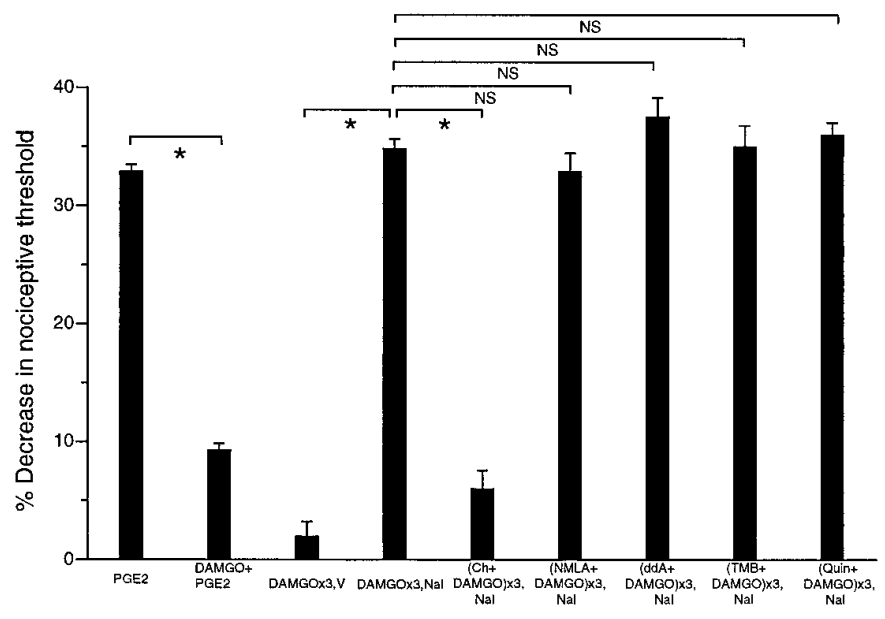

Figure 3. PKC but not NO, cAMP, or calcium plays a role in the development of peripheral opioid dependence. Effects of $\mathrm{PGE}_{2},\left(P G E_{2} ; n=16\right)$, DAMGO plus $\mathrm{PGE}_{2}\left(D A M G O+P G E_{2} ; n=16\right)$, three hourly injections of DAMGO followed by vehicle at the fourth hour $(D A M G O \times 3, V ; n=6)$, three hourly injections of DAMGO followed by naloxone at the fourth hour $(D A M G O \times 3, N A L ; n=12)$, three hourly injections of chelerythrine plus DAMGO followed by naloxone at the fourth hour $[(C h+D A M G O) \times 3, N A L$; $n=6]$, three hourly injections of NMLA plus DAMGO followed by naloxone at the fourth hour [ $(N M L A+D A M G O) \times 3, N A L ; n=12]$, three hourly injections of ddA plus DAMGO followed by naloxone at the fourth hour $[(d d A+D A M G O) \times 3, N A L ; n=6]$, three hourly injections of TMB-8 plus DAMGO followed by naloxone at the fourth hour $[(T M B+D A M G O) \times 3, N A L ; n=6]$, and three hourly injections of chelerythrine plus DAMGO followed by naloxone at the fourth hour $[($ Quin $+D A M G O) \times 3, N A L ; n=6]$ on mechanical paw withdrawal threshold in rats.

antinociception produced by the $\mu$-opioid agonist DAMGO (Aley et al., 1995). As reported previously (Aley and Levine, 1997b), we found that NO seems to be involved in tolerance, whereas PKC seems to be involved in dependence (Aley and Levine, 1997b). We have now shown that these systems are involved in development but not at all in expression or in conjunction with other systems for expression. Unlike us, previous investigators found that NO synthase inhibitors can reduce signs of opioid dependence, but nociception was not evaluated in any of

$\leftarrow$

Figure 1. A, Role of NO in development of peripheral opioid tolerance. Effects of $\mathrm{PGE}_{2}\left(100 \mathrm{ng} ; P_{G E_{2}} ; n=16\right)$, DAMGO $(1 \mu \mathrm{g})$ plus PGE $\left(D A M G O+P G E_{2} ; n=16\right)$, three hourly injections of DAMGO followed by DAMGO plus $\mathrm{PGE}_{2}$ at the fourth hour $\left(D A M G O \times 3, D A M G O+P G E_{2} ; n=\right.$ $12)$, saline $(n=6)$, NMLA $(1 \mu \mathrm{g})$ plus PGE PG $_{2}\left(N M L+P G E_{2} ; n=8\right)$, NMLA alone (NMLA; $\left.n=6\right)$, three hourly injections of NMLA followed by PGE 2 at the fourth hour $\left(N M L A \times 3, P G E_{2} ; n=6\right)$, and three hourly injections of NMLA plus DAMGO followed by DAMGO plus PGE 2 $\left[(N M L A+D A M G O) \times 3, D A M G O+P G E_{2} ; n=12\right]$ on mechanical paw withdrawal threshold in rats. In this and all subsequent figures, an asterisk indicates

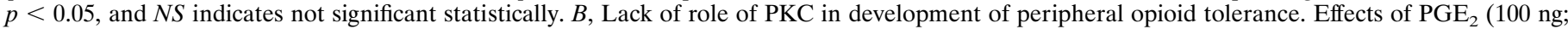
$\left.P G E_{2} ; n=16\right)$, DAMGO $(1 \mu \mathrm{g})$ plus $\mathrm{PGE}_{2}\left(D A M G O+P G E_{2} ; n=16\right)$, three hourly injections of DAMGO followed by DAMGO plus PGE 2 $\left(D A M G O \times 3, D A M G O+P G E_{2} ; n=12\right)$, chelerythrine $(1 \mu \mathrm{g})$ alone $(C h ; n=6)$, chelerythrine plus PGE $\left(C h+P G E_{2} ; n=6\right)$, chelerythrine plus DAMGO plus $\mathrm{PGE}_{2}\left(C h+D A M G O+P G E_{2} ; n=6\right)$, and three hourly injections of chelerythrine plus DAMGO followed by DAMGO plus PGE 2 $\left[(C h+D A M G O) \times 3, D A M G O+P G E_{2} ; n=6\right]$ on mechanical paw withdrawal threshold in rats. $C$, Lack of role of cAMP in development of peripheral opioid tolerance. Effects of $\mathrm{PGE}_{2}\left(100 \mathrm{ng} ; P G E_{2} ; n=16\right)$, DAMGO $(1 \mu \mathrm{g})$ plus $\mathrm{PGE}_{2}\left(D A M G O+P G E_{2} ; n=16\right)$, three hourly injections of DAMGO followed by DAMGO plus $\mathrm{PGE}_{2}\left(D A M G O \times 3, D A M G O+P G E_{2} ; n=12\right)$, ddA $(1 \mu \mathrm{g})$ plus $\mathrm{PGE}_{2}\left(d d A+P G E_{2} ; n=6\right)$, ddA alone $(d d A ; n=6)$, three hourly injections of ddA followed by $\mathrm{PGE}_{2}$ at the fourth hour $\left(d d A \times 3, P G E_{2} ; n=6\right)$, and three hourly injections of ddA ( $\left.1 \mu \mathrm{g}\right)$ plus DAMGO followed by DAMGO plus $\mathrm{PGE}_{2}$ at the fourth hour [ $\left.(d d A+D A M G O) \times 3, D A M G O+P G E_{2} ; n=12\right]$ on mechanical paw withdrawal threshold in rats. $D$, Lack of role of calcium in development of peripheral opioid tolerance. Effect of $\mathrm{PGE}_{2}\left(100 \mathrm{ng} ; P G E_{2} ; n=16\right), \mathrm{DAMGO}(1 \mu \mathrm{g})$ plus PGE $2\left(D A M G O+P G E_{2}\right.$;

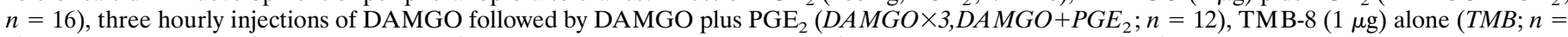
6), TMB-8 plus $\mathrm{PGE}_{2},\left(T M B+P G E_{2} ; n=6\right)$, TMB-8 plus DAMGO plus $\mathrm{PGE}_{2}\left(T M B+D A M G O+P G E_{2} ; n=6\right)$, and three hourly injections of TMB-8 plus DAMGO followed by DAMGO plus $\mathrm{PGE}_{2}$ at the fourth hour $\left[(T M B+D A M G O) \times 3, D A M G O+P G E_{2} ; n=6\right]$ on mechanical paw withdrawal threshold in rats. $E$, Lack of role of calcium in development of peripheral opioid tolerance. Effects of PGE $2\left(100 \mathrm{ng} ; P G E_{2} ; n=16\right)$, DAMGO $(1 \mu \mathrm{g})$ plus $\mathrm{PGE}_{2}\left(D A M G O+P G E_{2} ; n=16\right)$, three hourly injections of DAMGO followed by DAMGO plus $\mathrm{PGE}_{2}\left(D A M G O \times 3, D A M G O+P G E_{2} ; n=12\right)$, Quin-2 $(1 \mu \mathrm{g})$ alone (Quin; $n=6)$, Quin-2 plus $\mathrm{PGE}_{2}\left(\right.$ Quin $\left.+P G E_{2} ; n=6\right)$, Quin-2 plus DAMGO plus PGE $2\left(Q u i n+D A M G O+P G E_{2} ; n=6\right)$, and three hourly injections of Quin-2 plus DAMGO followed by DAMGO plus $\mathrm{PGE}_{2}$ at the fourth hour $\left[(Q u i n+D A M G O) \times 3, D A M G O+P G E_{2} ; n=6\right]$ on mechanical paw withdrawal threshold in rats. 


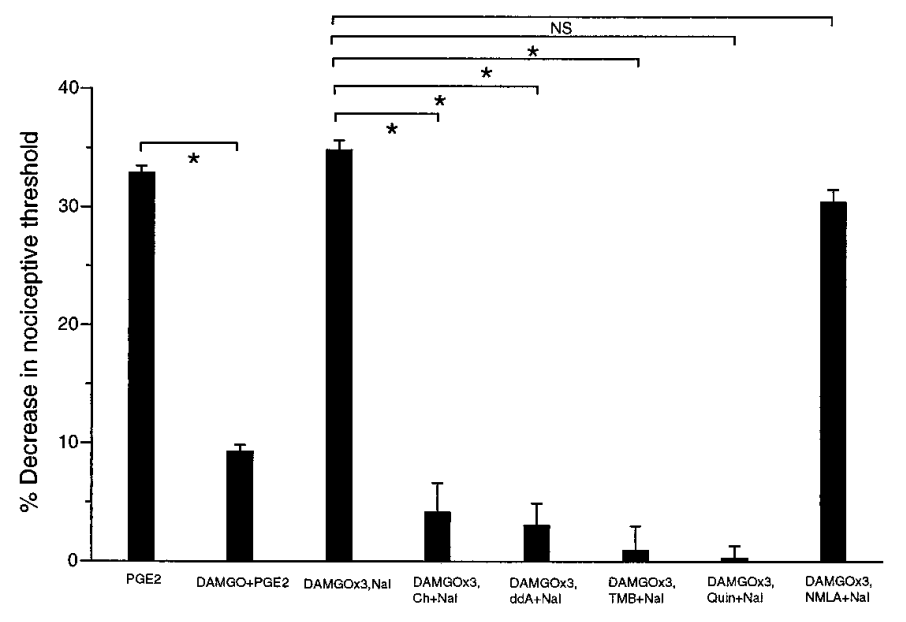

Figure 4. PKC, calcium, and cAMP, but not NO, play a role in expression of peripheral opioid dependence. Effects of $\mathrm{PGE}_{2}\left(P G E_{2} ; n=16\right)$, DAMGO plus $\mathrm{PGE}_{2}\left(D A M G O+P G E_{2} ; n=16\right)$, three hourly injections of DAMGO followed by naloxone at the fourth hour $(D A M G O \times 3, N A L$; $n=12$ ), three hourly injections of DAMGO followed by chelerythrine plus naloxone at the fourth hour $(D A M G O \times 3, C h+N A L ; n=10)$, three hourly injections of DAMGO followed by ddA plus naloxone at the fourth hour $(D A M G O \times 3, d d A+N A L ; n=6)$, three hourly injections of DAMGO followed by TMB-8 plus naloxone at the fourth hour $(D A M G O \times 3, T M B+N A L ; n=12)$, three hourly injections of DAMGO followed by Quin-2 plus naloxone at the fourth hour $(D A M G O \times 3$, Quin $+N A L ; n=12$ ), and three hourly injections of DAMGO followed by NMLA plus naloxone at the fourth hour $(D A M G O \times 3, N M L A+N A L ; n=$ 8 ) on mechanical paw withdrawal threshold in rats.

Table 1. Summary of mechanisms involved in development and expression of peripheral opioid tolerance and dependence

\begin{tabular}{lllll}
\cline { 1 - 1 } Dolerance & & & Dependence & \\
\cline { 1 - 1 } & $\mathrm{Ca}^{2+}$ & PKC & PKevelopment & Expression \\
\hline
\end{tabular}

these studies (e.g., Adams et al., 1993; Thorat et al., 1994; Bhargava, 1995; London et al., 1995). Our finding is consistent with the observation that although the NO synthase inhibitor NMLA prevents morphine tolerance, acutely it does prevent expression of tolerance (Kolesnikov et al., 1993; London et al., 1995; Dambisya and Lee, 1996; Dunbar and Yaksh, 1996). Interestingly, although mechanisms of development are distinct for tolerance and dependence, there are some common mechanisms of expression, namely calcium. Our results suggest that the development of tolerance and the development of dependence use discrete second messenger systems and that there is a partial overlap in mechanisms for the expression phase of tolerance and dependence. The generally reported observation of the coexistence of tolerance and dependence may be based in part on the contribution by this common second messenger system (Mao et al., 1995a,b).

Our results agree with the finding that chronic administration of calcium channel blockers can attenuate the expression of opioid tolerance in the CNS (Bongianni et al., 1986; Ruiz et al., 1993; Berstein and Welch, 1995; Diar et al., 1995; Diaz et al., 1995; Garaulet et al., 1996). Although the mechanism by which calcium is involved in expression of tolerance and dependence is uncertain, activation of PKC may influence neurons by changing conductances of ion channels (Alkon et al., 1986), including those for calcium. The importance of calcium may result from effects of opioids on calcium currents, an action shown to be mediated by G-proteins linked directly to a calcium channel (Hescheler et al., 1987). Also, during opioid withdrawal, phosphatidylinositol hydrolysis or PKC activity has been found to be greatly enhanced (Busquets et al., 1995; Mao et al., 1995a,b).

We observed in our experimental protocol that NMLA had an inhibitory effect on $\mathrm{PGE}_{2}$-induced hyperalgesia. Interestingly, in the DAMGO-tolerant animal, NMLA no longer exerted such an effect. This observation suggests that the NMLA effect may involve a common mechanism with one by which opioids act to produce tolerance.

In the experiments on naloxone-induced withdrawal hyperalgesia, ddA was able to prevent the expression of dependence. However, although not affecting baseline threshold, ddA inhibited $\mathrm{PGE}_{2}$-induced hyperalgesia. Therefore, although the findings with ddA suggest that cAMP is involved in expression of dependence, it is possible that the results reflect a less specific ability of ddA to blunt the production of hyperalgesic states, not specifically naloxone-induced hyperalgesia in DAMGO-treated rats.

In summary, the experiments presented here provide evidence that mechanisms reported previously to mediate opioid tolerance and dependence play differential roles in terms of development and expression in the model of $\mu$-opioid peripheral antinociception. Specifically, previously implicated second messengers are involved, and the second messenger calcium plays a role in expression of both tolerance and dependence. We hypothesize that these effects are occurring in the primary afferent nociceptor. However, although $\mathrm{PGE}_{2}$ hyperalgesia and DAMGO antinociception are known to occur by direct action on the primary afferent nociceptor, the sites of action of the second messenger inhibitors are not known. Therefore, intercellular effects are possible. In vitro studies would be needed to answer this question.

The presence of different second messengers mediating development and expression of opioid tolerance and dependence provides a new experimental construct for opioid pharmacology in general and suggests the possibility of novel therapeutic interventions that might prevent the development and continued presence of these two phenomena, which have a significant negative impact on the utility of opioid analgesia in humans.

\section{REFERENCES}

Adams ML, Kalicki JM, Meyer ER, Cicero TJ (1993) Inhibition of the morphine withdrawal syndrome by a nitric oxide synthase inhibitor, NG-nitro-L-arginine methyl ester. Life Sci 52:PL245-PL249.

Aley KO, Levine JD (1997a) Multiple receptors involved in peripheral $\alpha_{2}, \mu$, and A1 antinociception, tolerance, and withdrawal. J Neurosci $17: 735-744$.

Aley KO, Levine JD (1997b) Dissociation of tolerance and dependence for opioid peripheral antinociception in rats. J Neurosci 17:3907-3912.

Aley KO, Green PG, Levine JD (1995) Opioid and adenosine peripheral antinociception are subject to tolerance and withdrawal. J Neurosci 15:8031-8038.

Alkon DL, Kubota M, Neary JT, Naito S, Coulter D, Ramussen H (1986) $\mathrm{C}$-kinase activation prolongs $\mathrm{CA}^{++}$-dependent inactivation of $\mathrm{K}^{+}$currents. Biochem Biophys Res Commun 134:1245-1253.

Bernstein MA, Welch SP (1995) Alterations in L-type calcium channels in the brain and spinal cord of acutely treated and morphine-tolerant mice. Brain Res 696:83-88.

Bhargava HN (1995) Attenuation of tolerance to, and physical dependence on, morphine in the rat by inhibition of nitric oxide synthase. Gen Pharmacol 26:1049-1053.

Bongianni F, Carla V, Moroni F, Pellegrini-Giampietro DE (1986) Calcium channel inhibitors suppress the morphine-withdrawal in rats. $\mathrm{Br} \mathbf{J}$ Pharmacol 88:561-567. 
Busquets X, Escriba PV, Sastre M, Garcia-Sevilla JA (1995) Loss of protein kinase $\mathrm{C}$-alpha beta in brain of heroin addicts and morphinedependent rats. J Neurochem 64:247-252.

Dambisya YM, Lee TL (1996) Role of nitric oxide in the induction and expression of morphine tolerance and dependence in mice. Br J Pharmacol 117:914-918.

Diaz A, Ruiz F, Florez J, Hurlé MA, Pazos A (1995) Mu-opioid receptor regulation during opioid tolerance and supersensitivity in rat central nervous system. J Pharmacol Exp Ther 274:1545-1551.

Dunbar S, Yaksh TL (1996) Effect of spinal infusion of L-NAME, a nitric oxide synthase inhibitor, on spinal tolerance and dependence induced by chronic intrathecal morphine in the rat. Neurosci Lett 207:33-36.

Garaulet JV, Laorden ML, Milanes MV (1996) Effect of chronic administration of dihydropyridine $\mathrm{Ca}^{2+}$ channel ligands on sufentanilinduced tolerance to mu- and kappa-opioid agonists in the guinea pig ileum myenteric plexus. Regul Pept 63:1-8.

Herman BH, Vocci F, Bridge P (1995) The effects of NMDA receptor antagonists and nitric oxide synthase inhibitors on opioid tolerance and withdrawal. Medication development issues for opiate addiction. Neuropsychopharmacology 13:269-293.

Hescheler J, Rosenthal W, Trauwein W, Schultz G (1987) The GTPbinding protein, $G_{o}$, regulates neuronal calcium channels. Nature 325:445-447.

Honore P, Catheline G, LeGuen S, Besson JM (1997) Chronic treatment with systemic morphine induced tolerance to the systemic and peripheral antinociceptive effects of morphine on both carrageenan induced mechanical hyperalgesia and spinal c-Fos expression in awake rats. Pain 71:99-108.

Kolesnikov YA, Pick CG, Ciszewska G, Pasternak GW (1993) Blockade of tolerance to morphine but not to kappa opioids by a nitric oxide synthase inhibitor. Proc Natl Acad Sci USA 90:5162-5166.

Kolesnikov YA, Jain S, Wilson R, Pasternak GW (1996) Peripheral morphine analgesia: synergy with central sites and a target of morphine tolerance. J Pharmacol Exp Ther 279:502-506.

Levine JD, Taiwo YO (1989) Involvement of the mu-opiate receptor in peripheral analgesia. Neuroscience 32:571-575.
London ED, Kimes AS, Vaupel DB (1995) Inhibitors of nitric oxide synthase and the opioid withdrawal syndrome. NIDA Res Monogr 147:170-181.

Mao J, Price D, Phillips L, Lu J, Mayer D (1995a) Increases in protein kinase $\mathrm{C}$ gamma immunoreactivity in the spinal cord of rats associated with tolerance to the analgesic effects of morphine. Brain Res 677:257-267.

Mao J, Price DD, Mayer DJ (1995b) Experimental mononeuropathy reduces the antinociceptive effects of morphine: implications for common intracellular mechanisms involved in morphine tolerance and neuropathic pain. Pain 61:353-364.

Narita M, Mizoguchi H, Tseng LF (1995) Inhibition of protein kinase C, but not of protein kinase A, blocks the development of acute antinociceptive tolerance to an intrathecally administered mu-opioid receptor agonist in the mouse. Eur J Pharmacol 280:R1-R3.

Pasternak GW, Kolesnikov YA, Babey AM (1995) Perspectives on the $N$-methyl-D-aspartate/nitric oxide cascade and opioid tolerance. Neuropsychopharmacology 13:309-313.

Ruiz F, Dierssen M, Florez J, Hurle MA (1993) Potentiation of acute opioid-induced respiratory depression and reversal of tolerance by the calcium antagonist nimodipine in awake rats. Naunyn Schmiedebergs Arch Pharmacol 348:633-637.

Stein C (1991) Peripheral analgesic actions of opioids. J Pain Symptom Management 6:119-124.

Stein C, Schäfer M, Hassan AH (1995) Peripheral opioid receptors. Ann Med 27:219-221.

Thorat SN, Barjavel MJ, Matwyshyn GA, Bhargava HN (1994) Comparative effects of NG-monomethyl-L-arginine and MK-801 on the abstinence syndrome in morphine-dependent mice. Brain Res 642:153-159.

Vaupel DB, Kimes AS, London ED (1995) Nitric oxide synthase inhibitors. Preclinical studies of potential use for treatment of opioid withdrawal. Neuropsychopharmacology 13:315-322.

Wang Z, Arden J, Sadee W (1996) Basal phosphorylation of mu opioid receptor is agonist modulated and $\mathrm{Ca}^{2+}$-dependent. FEBS Lett 387: 53-57. 